\title{
Concept Mapping Strategy: A Strategic Alternative to the Matter of Spontaneous Speaking of Iranian Intermediate EFL Learners
}

\author{
Hooshang Khoshsima ${ }^{1}$, Amin Saed ${ }^{1, *}$, Afsaneh Hakimzadeh ${ }^{2}$ \\ ${ }^{1}$ English Language Department, Chabahar Maritime University, Chabahar, Iran \\ ${ }^{2}$ Chabahar Maritime University, Chabahar, Iran
}

Email address:

Amin.Saed@cmu.ac.ir (A. Saed), afsanehhakimzadeh@yahoo.com (A. Hakimzadeh)

\section{To cite this article:}

Hooshang Khoshsima, Amin Saed, Afsaneh Hakimzadeh. Concept Mapping Strategy: A Strategic Alternative to the Matter of Spontaneous Speaking of Iranian Intermediate EFL Learners. International Journal of Language and Linguistics. Vol. 4, No. 1, 2016, pp. 1-8. doi: $10.11648 /$ j.ijl1.20160401.11

\begin{abstract}
This study investigated the effectiveness of Concept Mapping used as a learning strategy to improve the spontaneous speaking of Iranian intermediate EFL learners. To this end, forty EFL learners were selected based on their performance on a standardized proficiency test and randomly assigned into two experimental and control groups. The speaking pretest and posttest were scored according to the IELTS Speaking Band checklist. Throughout a twenty two session treatment, the participants in the experimental group used concept mapping strategy, but those in the control group did not practice this strategy and worked on other common activities instead. Finally, a speaking posttest was taken to test the performance of the two groups. Both pretest and posttest were administered by three examiners. Calculating the inter-rater reliability of the examiners showed that there is a significant correlation between raters' scores on pretest and posttest of both groups. At last, the results of independent-sample t-test showed significantly greater gains of the experimental group than the control group. Therefore, results showed that concept mapping had statistically significant effect on spontaneous speaking of intermediate EFL learners.
\end{abstract}

Keywords: Spontaneous Speaking, Concept Mapping, Cognitive Strategies, Metacognitive Strategies

\section{Introduction}

Speaking ability plays a vital role in second language learning and it has become increasingly the major goal of most EFL learners due to the demand of international communication, business, trade, science, and communication. The importance of communication have impelled non-native speakers specially EFL learners all over the world to improve speaking to gain better communication in recent years. Demands of speaking communicatively and its influence on EFL learner's success in education highlights the importance of speaking among the other skills. However, lack of immediate exposure and consequently relying on academic situation has become a disaster for most EFL learners. Accordingly, this has led to an inadequacy in expressing their language knowledge spontaneously.

On the other hand, learners sometimes start an utterance, and during the speaking process learners reach a point where they can't find the right word or thinks better of a word, and needs time to find a suitable alternative. Hence, majority of EFL learners attempt to develop speaking through a prescribed, rehearsed format of the topic the speaker will be speaking on, but Spontaneous acts are not planned or arranged. Spontaneous speaking occurs when someone suddenly wants to present himself and without any rehearsed format just starts talking about the subject. According to Shriberg (2005), Spontaneous speech is stream of words which is remarkably efficient, imposes minimal cognitive load, and carries a wealth of information at multiple levels.

Considering the great tendency for developing the speaking skill, it is essential to discover which ways or skills will best help learners to improve their speaking spontaneously. In this vein, along with vexing a critical importance of speaking in learner's success or failure in communication and education, the arrival of language learning strategies formed a great shift in researcher's 
perspective in order to give a sense of unfolding debates surrounding this challenging area. After introduction of LLS into the field of second language studies, speaking introduced as a complex process which implies learning strategies involve some cognitive and organizational process that each speaker begins to speaking should be involved them. From this idea, not only speaking is more than simply grammatical comprehension and vocabulary memorization, but it is a complex cognitive process, through which learners need to process some strategies involves planning the message, finding word and phrases, using background knowledge, and ability to self-correction and self- monitoring. According to Levelt (1989), speaking involves the processing of a considerable amount of data in a limited period of time.

Therefore, a basic part of developing speaking ability is utilizing learning strategies with the aim of training learners to be able to take active role in their learning process and managing their thought. Findings of researches reveal that Well-developed speakers are those who know and apply the learning strategies. Park (1995) supported this idea by stating that learning strategies as the mental activities that people use when they study to help themselves acquire, or remember incoming knowledge more efficiency. Whereas utilizing the strategies have significant role on speaking ability, many studies have been done to identifying the best strategy to improve the speaking ability of EFL learners. For this aim, current study attempts to explore the effectiveness of concept mapping on spontaneous speaking of Iranian intermediate EFL students. Basis of concept mapping strategy as cited in Nirmala (2011) is assimilation theory of Ausubel which was developed by Novak for the first time at 1970. Assimilation theory of Ausubel emphasized the importance of prior knowledge which should be connected to new concepts that would lead to meaningful learning. The rationale behind the use of concept mapping in speaking can be expressed on its effect on planning the message, finding appropriate words and phrases and organizing the knowledge. Concept mapping provide the speaker opportunity to accelerate the comprehension and production and gradually leads to spontaneous speaking.

For this aim, the question to be investigated in this study is whether concept mapping strategy effects spontaneous speaking of Iranian intermediate EFL learners. It worths mentioning that age and gender were not taken in consideration in this study.

\section{Speaking}

Speaking in L2 education is usually the first step to learn the English language and by improvement of communication strategies receives more attention rather than other skills (Nunan, 2001; Richards and Renandya, 2002). Moreover, Speaking as the new parameter used to determine success in second/foreign language education programs. On the other hand, student's success or lack of success in ESL/EFL was judged by the extent of the language they produced. According to Riggenback \& Lazaraton (1991), students of second/foreign language education programs are considered successful if they can communicate effectively in the language.

Cicognani (2000), argued that speaking is process of unifying the numerous kind of information, navigating them in mind and consolidating the information for problem solving and interaction. By having communicative purpose, and in the context of EFL learning, the ability to convey messages in natural communication and ability to speak spontaneously have paramount importance. According to Shumin (2002) speaking a language is especially difficult for foreign language learners because of effective oral communication require the ability to use the language appropriately in social interaction. Spontaneous speaking is a complex process in which speakers try to employing their knowledge, encoding their own meaning and recombine elements with appropriate words and phrases without any rehearsing. Hence, due to the large number of EFL learners who want to use English for communicative purposes teaching of speaking skill is also important. By developing learning strategies and shifting the emphasize on learners active involvement on learning process, Teachers should analyze, evaluate and synthesize utilizing appropriate strategy that encourage students to operate at higher levels of abstraction (Stanley D. Ivie, 1998). The question of which strategy is more effective than another is, in itself, a problem. Current study attempt to consider concept mapping as a metacognitive strategy can be used as learning and creative tool and its effect on speaking spontaneous.

\subsection{Learning Strategies}

In recent years there has been a shift in focus from the teacher to the learner and there is an exclusive focus on how learners go about their learning tasks in a second or foreign language. Teaching learning strategies helps students to improve their abilities to take full advantage of opportunities to learn. Findings of researches show that learners who do not know or use good learning strategies often fail in their effort in mastering second language. Successful language learners tend to select strategies that work well together in a highly orchestrated way, tailored to the requirements of the language task (Chamut \& Kupper, 1989). Successful learners can easily explain the strategies they use and why they employ them (Chamot \& O'Malley, 1990). This is why learning strategy instruction focuses on making the students more active learners by teaching them how to learn and how to use what they have learned to solve problems and be successful. Oxford (1990) defines learning strategies as specific actions taken by the learner to make learning easier, faster, more enjoyable, more self-directed and more transferable to new situations. (p.9).According to (Nunan, 2001)," strategies are mental and communicative procedures learners use in order to learn and use language"(P.171). There is various numbers of strategies that can help students to become better learners. These strategies include meaningful learning, organizing, identifying important information, and summarizing (Pressley, 1982). Use of appropriate language 
learning strategies often proficiency or achievement overall or in specific skill areas (Oxford et al., 1993; Thompson \& Rubin, 1996). Research supports the effectiveness of using L2 learning strategies on learning process. Recent study on effect of interactional and transactional speaking strategies on teaching speaking skills to Iranian EFL learners at senior high school showed that the use of transactional activities in speaking skill could be beneficial activities (Zarei.et al, 2014) Other study carried out on the effect of learning strategies on the speaking ability of Iranian students in the context of language institutes. The findings of this study showed that instruction of the strategies makes a positive significant difference in the learners' use of the strategies in private language centers (Jabbari, et al, 2014). Hendariani (2013) developed a model of learning strategy of speaking English at college. Finding of the study shows that the appropriate model of learning strategy of speaking for the learnes is the one that can help them overcome their psychological, social, managerial, and linguistic problems before, while and after speaking and the developed learning strategy model is found effective in improving the students' speaking skills. Sri Wahyuni( 2013) examine the L2 speaking strategies on Indonesian EFL tertiary students across proficiency and gender. The study demonstrates that the students used a wide range of strategies that spread over six strategy groups, favoring metacognitive strategies. The study reveals a significant relationship between L2 proficiency and students' overall strategy use. It also shows that speaking proficiency and gender significantly affected the use of affective strategies only. The study also demonstrates that the students used strategies consciously, confidently, effort fully, or persistently because of the usefulness of the strategies or pleasure in using them. Finding of studies carried out on speaking problem of EFL learner's shows that strengthening cognitive and metacognitive structures helps students retain information longer and use them for develop the speaking.

\subsection{Cognitive and Metacognitive Strategies}

The need for spontaneous second language speaker arises from interest in finding better ways to help EFL learners by explaining good strategic learners to them. It is greatly improved that language learners outperform better by understanding learning strategies. Learners want to use of what they have in their minds. The problematic point about EFL learners is lack of ability to organizing the information into an integrated system and using them in appropriate situations. Furthermore, results of researches reveals that well-tailored combinations of strategies often are more effective than single strategies. In this vein, Purpura (1999) found that metacognitive strategies had a significant, positive, direct effect on cognitive strategy use. According to Sabuncuğlu (2011)" Cognitive strategies enable the learner to understand and produce new language and Metacognitive strategies allow learners to control their own learning through organizing, planning and evaluation and are employed for managing the learning process overall." Cognitive (e.g., translating, analyzing) and metacognitive (e.g., planning, organizing) strategies are often used together, supporting each other (O'Malley \& Chamot, 1990). Current research supports the effectiveness of using concept mapping strategy which serves as a cognitive and metacognitive strategy to help learners organize their cognitive frameworks into more powerful integrated patterns.

\subsection{Concept Mapping}

Concept mapping is a cognitive and meta-learning strategy that can be used to develop students' capacity to learn independently (Chiou, 2008). The basis of concept mapping is assimilation theory of Ausubel with the aim of meaningful learning. According to Novak concept mapping are graphical organizing consist of concept, positioned in some circles or boxes, and the relationships between these boxes are shown by connecting line linking two concepts. These lines represent the relationship between the two concepts. When concepts and linking words are carefully chosen, these maps can be useful tools for observing a subtle distinction of meaning, helping users to organize their thinking, and summarizing subjects of study. By summarizing the subject using keywords and linking these keywords to each other to create a map of relationships, individuals are able to clarify for themselves what is involved in a certain subject, and it can help them to effective use of that information. The main characteristic of concept mapping is its hierarchical structure. In this model most general concepts represents at the top of the map and the more specific and less general concepts arranged by rank below (Novak \& Cañas, 2008). These concepts and their relationships can be hierarchically organized to build up knowledge, which is a human construct (Gowin, 1981) Hierarchical representation of concept maps give students opportunity to think about the connection between the terms being learned, organize their thoughts, visualize the relationship between concepts and reflect on their understanding. As Stanley D. Ivie (1998) stated "Teaching and learning, are largely matters of erecting cognitive structures to hold new information. By placing information into its proper box, we are better able to retain it for future use. Similarly, forgetting occurs when the smaller boxes which being made of less durable cognitive stuff fall apart and become incorporated into the larger boxes. Cognitive structure facilitates the learning and retention of new information and helps to well organize the information as well as accelerate use them. Many researches on concept mapping have proved that it can improve meaningful learning and help learners learn independently (Cliburn, 1990; Heinze-Fry \& Novak, 1990; Kinchin, 2003; Mintzes, Wandersee, \& Novak, 2001; Novak, 1990; Novak, Gowin, \& Johansen, 1983; Okebukola \& Jegede, 1988; Trowbridge \& Wandersee, 1998).

Various studies have been carried out on effect of concept mapping on different skills. Palmer, Boon and Spencer (2014) have conducted a research on effects of concept mapping Instruction on the Vocabulary Acquisition Skills of SeventhGraders with Mild Disabilities. Results revealed marked improvements for all of the students in their learning of the 
content area related vocabulary words associated with the use of the concept mapping model over the dictionary approach. Cheema and Mirza(2013) replicates and analyze effect of concept mapping, a constructivism based learning strategy, on academic performance of 7 th grade students in the subject of general science Results showed that the male and female students taught through concept mapping performed better than the students taught through traditional teaching methods. The other studied carried out on use of concept map in foreign language education (Moreira \& Moreira, 2011)They used concept maps as an instructional tool to foster the construction of knowledge in Foreign Language Education classes, in an attempt to help students organize, interact, and share meanings derived from their reading of literary texts. The study suggests that learning of poems and literature can get closer to the students' reality and become more meaningful to them by using concept map. Gonsooly and Hosseinpour (2009) examined the effect of concept mapping on EFL speaking fluency. Results showed the concept mapping had significant effect on speaking fluency of intermediate EFL students. Chularut and DeBacker (2003) examined the influence of concept mapping on achievement, self-regulation, and self-efficacy in EFL students. Chang, Sung and Chen (2002) investigated the effect of concept mapping on student's text comprehension and summarization. The findings revealed that concept mapping improved reading comprehension and summarization. In contrast, as cited in Fahim et.al, (2012), concept mapping has been critiqued by the knowledge representation community for being informal. Considering plethora studies carried out on effect of concept mapping on different areas, but a few investigations carried out on speaking. No studied have been done on effect of concept mapping on speaking spontaneously till now. Present study investigated the effect concept mapping on speaking spontaneous of intermediate EFL learners.

\section{Methodology}

\subsection{Subjects}

The participants in this study were 40 students from two classes in English language center of Chabahar Maritime University, Iran enrolled in the second semester of 2014. One class of 20students was randomly assigned as the experimental group; the other class of 20 students was used as the control group. Participants ranged in age from 17 to 28 years, and included 29 males and 11 females. They were not classified in term of age and gender. Since only intermediate students were required for the purpose of the current study, an objective placement test was taken to attain a homogeneous sample. The experimental class received concept mapping for treatment, while the control class were not exposed to concept mapping but followed the traditional curriculum activities. The teacher and the textbooks for both classes were the same to avoid any disarray on the experiment. None of the students reported previous experience in concept mapping.

\subsection{Materials}

The main material of study utilized for both experimental and control groups were taken from the Top Notch series.

\subsubsection{Instrumentation}

An English placement test, a proficiency pretest and posttest were administered to collect the required data. And finally, the IELTS Speaking band checklist was used to rate both groups.

\subsubsection{English Placement Test}

For the purpose of the study an intermediate placement test was used to ensure the homogeneity of the samples. The Nelson English Language Test was administered to the participants. The aim was to evaluate their language proficiency in order to choose the intermediate students.

\subsubsection{Pretest and Posttest}

Speaking section of Longman Preparation Course for the TOFEL was administered to the students for the pretest and posttest. The participants took part in a twenty-minute interview with the aim of considering the effects of teaching concept mapping on their speaking ability. Subjects had to speak for one minute about the topic. They should support the topic statement, and use transitions to show how the ideas are related. The criterion for scorers was the IELTS Speaking Band checklist There were three examiners to rate them. In cases that the interviewer and the other two raters agreed on the scores the interview were taped and a decision was made. In the case of disagreement, the tape was sent to a third rater. Finally, a standard and reliable test similar to that of pretest was used for posttest at the end of treatment.

\subsection{Procedures}

The current study as a quasi-experimental research started at second semester of 2014. The study was conducted for twenty two sessions during five and half weeks. Each session was one hour and thirty and three times in a week. The Top Notch textbook was the main book. Five units consisting four lessons were taught during the twenty two sessions. All selected topics were at intermediate level. For the aim of checking the learner's homogeneity, the Nelson English language test was administered. Then, the participants were divided into two groups of control and experimental. Once the pretest was learners in the experimental group were engaged in a treatment which lasted for twenty two sessions. At the beginning of treatment, the researcher first explained why concept mapping is a useful tool for learning, explicitly instructed concept mapping to the students and modeled some examples. In each session, students participated in speaking activities including retelling passages, conversations and some listening conversations. Since concept map techniques implied equivalent and synonyms in each session, the researcher explained new and unfamiliar vocabularies for students. In the first session, students were 
asked to summarize the passages to be taught, note taking from the topic and choosing key word related to main idea to design a concept map. They were asked words or concepts related to the main idea and placed them in the concept maps. The researcher then corrected student-constructed concept maps.

At last, learners were asked to use these modified concept maps as review tools to present the topics to the other students. They had to talk about topics that are to be taught for 10 minutes in the next session. In the next sessions, after a warm up and short review the researcher prepared some feedback by considering the learners comments, problems and questions. Then the instructor went through the new units This procedure was the same for following sessions. The above procedure was repeated until the end treatment.

During these five and half weeks of experiment, while the experimental group participated in the concept mapping program, the control group didn't receive concept mapping instruction and they received the traditional instructions. The other procedures like time limits, the content of completion test and interview (in pre and posttest) were the same for control group. In the control group, the taught from the textbook using teacher made methods. After studding each unit, the new vocabularies and structures were explained for students. Participants were asked to listen to the passage and note taking. Then participants were asked to work on some questions related to the passage and conversation they listened to answer them. Participants suggested working in group and practice the conversations. They had to talk about the passages they studied in 10 minutes for the other peer groups. This procedure was also repeated until the end of the textbook. The implementation period was the same as the experimental group. At the end of twenty two sessions of instructions, a test similar to the pretest was administered to the experimental and control groups. Both pretest and posttest were examined by three examiners and rated according to the IELTS Speaking Band checklist.

\subsection{Data Analysis}

As mentioned, to see whether the two groups were at the same level of ability, a proficiency test was administered to both Control and Experimental groups. As the results clearly show, the two groups were almost at the same level of proficiency. The results of the analysis are shown in the following Tables.

Table 1. Independent Samples Test of the control and the experimental group at the pretest Group Statistics.

\begin{tabular}{llllll}
\hline & groups & N & Mean & $\begin{array}{l}\text { Std. } \\
\text { Deviation }\end{array}$ & $\begin{array}{l}\text { Std. Error } \\
\text { Mean }\end{array}$ \\
\hline \multirow{2}{*}{ Scores } & Control & 20 & 27.2000 & 8.75755 & 1.95825 \\
& Experimental & 20 & 28.5500 & 9.42268 & 2.10697 \\
\hline
\end{tabular}

Table 2. Independent Samples Test.

\begin{tabular}{|c|c|c|c|c|c|c|c|c|c|c|}
\hline & & \multicolumn{2}{|c|}{$\begin{array}{l}\text { Levene's Test for } \\
\text { Equality of Variances }\end{array}$} & \multicolumn{7}{|c|}{ t-test for Equality of Means } \\
\hline & & \multirow[t]{2}{*}{$\mathbf{F}$} & \multirow[t]{2}{*}{ Sig. } & \multirow[t]{2}{*}{$\mathbf{t}$} & \multirow[t]{2}{*}{ df } & \multirow{2}{*}{$\begin{array}{l}\text { Sig. } \\
\text { (2-tailed) }\end{array}$} & \multirow{2}{*}{$\begin{array}{l}\text { Mean } \\
\text { Difference }\end{array}$} & \multirow{2}{*}{$\begin{array}{l}\text { Std. Error } \\
\text { Difference }\end{array}$} & \multicolumn{2}{|c|}{$\begin{array}{l}\text { 95\% Confidence Interval } \\
\text { of the Difference }\end{array}$} \\
\hline & & & & & & & & & Lower & Upper \\
\hline \multirow{2}{*}{ Scores } & $\begin{array}{l}\text { Equal variances } \\
\text { assumed }\end{array}$ & .074 & .788 & -.469 & 38 & .642 & -1.35000 & 2.87647 & -7.17311 & 4.47311 \\
\hline & $\begin{array}{l}\text { Equal variances } \\
\text { not assumed }\end{array}$ & & & -.469 & 37.798 & .642 & -1.35000 & 2.87647 & -7.17413 & 4.47413 \\
\hline
\end{tabular}

The analysis of the data obtain from the study was carried out using Pearson correlation, mean score, and independent sample t-test. A Pearson-product moment correlation was performed in order to check the inter-rater reliability of pretest scores which were independently reported by two examiners. The results which are provided in table 1 revealed that there is a significant relationship between the scores of pretest obtained by two raters in the experimental $\operatorname{group}(r$ $=.96, p<0.05$ ). Therefore, the inter-rater reliability of scores for the experimental group is highly significant.

Table 3. Inter-Rater reliability: Experimental Pretest.

\begin{tabular}{llll}
\hline & & Pater1 & Rater2 \\
\hline \multirow{4}{*}{ Pater1 } & Pearson Correlation & 1 & $.962 * *$ \\
& Sig. (2-tailed) & & .000 \\
& N & 20 & 19 \\
& Pearson Correlation & $.962 * *$ & 1 \\
\multirow{5}{*}{ Rater2 } & Sig. (2-tailed) & .000 & \\
& N & 19 & 19 \\
\hline
\end{tabular}

Also, the inter-rater reliability of pretest scores of control group which was calculated among two sets of pretest scores of control group showed that there is a high significant relationship between the scores of pretest obtained by two raters in control group $(r=.97, p<0.05)$.

Table 4. Inter- Rater reliability: Experimental Posttest.

\begin{tabular}{llll}
\hline & & Pater1 & Rater2 \\
\hline \multirow{4}{*}{ Pater1 } & Pearson Correlation & 1 & $.975^{* *}$ \\
& Sig. (2-tailed) & & .000 \\
& N & 20 & 20 \\
& Pearson Correlation & $.975^{* *}$ & 1 \\
\multirow{5}{*}{ Rater2 } & Sig. (2-tailed) & .000 & \\
& $\mathrm{~N}$ & 20 & 20 \\
\hline
\end{tabular}

The inter-rater reliability of the experimental group's performance on posttest was also calculated by means of Pearson correlation. The results of statistical analysis are provided in Table 3 showed that there is a strong and significant correlation between two raters' scores on posttest of experimental group $(\mathrm{r}=.96, \mathrm{p}<.05)$. 
Table 5. Inter-Rater reliability: Control Pretest.

\begin{tabular}{llll}
\hline & & Pater1 & Rater2 \\
\hline \multirow{4}{*}{ Pater1 } & Pearson Correlation & 1 & $.962^{* *}$ \\
& Sig. (2-tailed) & & .000 \\
& N & 20 & 20 \\
& Pearson Correlation & $.962^{* *}$ & 1 \\
\multirow{4}{*}{ Rater2 } & Sig. (2-tailed) & .000 & \\
& N & 20 & 20 \\
\hline
\end{tabular}

Also, considering the inter-rater reliability of the control group's performance on posttest was calculated by means of Pearson correlation revealed the significance relationship between the scores of posttest obtained by two raters in control group $(r=0.94, p<0.05)$.

Table 6. Inter-Rater reliability: Control Posttest.

\begin{tabular}{llll}
\hline & & Pater1 & Rater2 \\
\hline \multirow{3}{*}{ Pater1 } & Pearson Correlation & 1 & $.949^{* *}$ \\
& Sig. (2-tailed) & & .000 \\
& N & 20 & 20 \\
& Pearson Correlation & $.949^{* *}$ & 1 \\
\multirow{2}{*}{ Rater2 } & Sig. (2-tailed) & .000 & \\
& N & 20 & 20 \\
\hline
\end{tabular}

Results of inter-rater reliability supported the significance relationship between the scores of pretest and post test in both groups. Therefore, one range of scores was selected and analyzed by independent t-test to see whether of both groups outperforemed in spontaneous speaking.

Table 7 displays the results of pretest among control and experimental. As the table indicates based on students' performance on Longman Preparation Course for the TOFEL Test, there was no statistically significant difference between the two groups (p .642>.05).

The results of pretest and posttest were calculated by SPSS software to show the differences between two groups.

After five and half weeks of instruction, all participants of both control and experimental groups were given the Longman Preparation Course for the TOFEL Test as posttest which was the same as pretest. In order to see whether the treatment implemented to the experimental group had significant effect or not, the mean score of the control and experimental were compared. An independent T-test was run between the scores of posttest.

\section{Discussion}

As previously mentioned, 40 students participated in current study were studying English as a foreign language in English Language Centered of Chabahar Maritime University.

A standardized Nelson proficiency test was administered in order to determine the level of proficiency of students as intermediate. Before receiving any instruction, in order to make sure that there is no significant difference between the two groups in their speaking ability, the performance of all participants was examined by three examiners. After the treatment, a similar test was taken and scores were recorded by the raters. Among three ranges of scores, two close ranges were selected and the inter-rater reliability of scores was calculated. Because of significant inter-rater reliability of scores, one set of scores of pretest and posttest were analyzed by an independent t-test to check the groups' achievement in spontaneous speaking.

The mean for each group was analyzed. The results of data analysis revealed a significant difference in the performance of the students in the control and experimental group. Therefore the results advocated the idea suggested about the effectiveness of concept mapping strategy on language learning. Good language learners are practically interested in finding better strategies for better understanding and meaningful learning. Meaningful learning happens when a person concisely and explicitly ties new knowledge to relevant concept. We can reach to meaningful learning by storing the information in long-term memory in association with related pieces of information. As it was revealed in the data, there was a relationship between speaking skill and utilizing concept mapping strategy. On the other hand, concept mapping enables the expansion of the students' meaningful learning, establishes a bridge between the way learners learn knowledge and externalization and cognize the learning knowledge.

Concept mapping has been used for more than 25 years as an important tool for meaningful learning in educational settings (Wheeler \& Collins, 2003).

Current study along with the previous related studies emphasized the effectiveness of learning strategies on students' language learning particularly speaking skill.

As mentioned before concept mapping as a graphical tool allows learners to do a schematic and it makes easy to understand and represent their knowledge in a particular domain. As Novak and Gowin (1983) put it: "concept maps are visual tools that show the most important ideas and reflect the linkage of concepts or facts within a passage and help students generate question about the content and understand better"(p.15).

Finding of research shows that concept mapping is a useful tool for assessing the learner's improvement is a special skill. Through the concept mapping strategy, teacher can identify the learner's weakness and make the effort to solve the problem particularly for the aim of the current study. By explicit learning the concept mapping strategy, learners are given an opportunity for better organizing the information, choosing an appropriate vocabulary with focus on key concepts and effective representation. By recognizing which domain is problematic in speaking stages, teacher can help the students to remove the challenging part and enhance the speaking opportunity with teaching learner to focus on key words and organize them in speaking.

Finding of study in experimental group showed that learners retain the key words in their mind consciously. Furthermore relevant key words in concept mapping made the conversation too easy to understand and even facilitate speaking spontaneous about a special domain. A hierarchal nature of concept mapping and arrangement of concepts by 
the way that special concept usually comes, help students to direct their ideas when they are speaking.

Generally, the results of the current study indicate that concept mapping as a meta-cognitive strategy can be effective for cognitive objectives. Using metacognitive strategies help students to organize language knowledge and evaluate their own learning, allow them to enhance speaking skill of students in spontaneous manner, discuss their feelings with someone else and take risks with their language.

\section{Conclusion}

Speaking skill is regarded as one of the most important part of language learning and can be regarded as successful scale for most learners whether in real communication or in academic situation. But in spite of possessing a certain amount of knowledge of language most of students meet with many problems and difficulties in expressing their messages in a coherent and spontaneous manner. Most students are not being able to use the knowledge they learned in different situations and are passive in their own learning.

Many debates have been held in relation to the learning strategies to remove learner's problems, especially for the speaking skill. Furthermore many studies have been conducted about different kins strategies to amend the English speaking weaknesses of Iranian students. Current study attempted to figure out the effect of concept mapping on Iranian intermediate EFL learners' speaking skill. Furthermore, the study emphasized the importance of learning strategies in the academic environments.

Findings of the current study showed that exposing students to concept mapping involves them in their own comprehension from the topic and involve them in the conversation. Planning the message, finding words and phrases, using background knowledge, having the ability of self-correction and self- monitoring are important steps in speaking progress. Brainstorming for key words related to the topic for making concept map had effective consequences for enhancing and managing the spontaneous speaking.

According to Fahim and Tabatabaian (2012), concept maps ought to be used in classroom settings as a part of education and assessment tools. The present study suggested concept mapping as a good supplementary strategy for teachers to provide learners with the opportunity to be acquainted with concept mapping and compare it with the other technique.

\section{References}

[1] D. Ausubel, The Psychology of meaningful verbal learning, New York: Grune and Stratton, 1963.

[2] A. U. Chamut and L. Kupper, "Learning strategies in foreign language instruction," Foreign Language Annals, pp. 13-24, 1989.

[3] A. U. Chamot and J. M. O'Malley, Learning strategies in second language acquisi $\neg$ tion, cambridge: cambridge University Press, 1990.
[4] D. Nunan, Second language Teaching and Learning, Boston, massachusetts: Heinle \& Heinle Publishers, 2001.

[5] C. C. Chiou, "The effect of concept mapping on students' learning achievements and interests," Taylor \& Francis Groups, p. 375-387, 2008.

[6] J. Novak and A. Cañas, "The theory underlying concept maps and how to construct and use them," Technical Report IHMC, 2008.

[7] D. B. Gowin, Educating, Ithaca: Cornell University Press, 1981.

[8] M. M. Moreira and S. M. Moreira, "Meaningful learning: USE of concept maps in foreign language," Aprendizagem Significativa em Revista/Meaningful Learning Review, pp. 6475, 2011.

[9] L. Wheeler and S. Collins, "The influence of concept mapping on critical thinking skills in baccalaureate," Journal of professional Nursing, pp. 339-346, 2003.

[10] Park.S, "Implication of learning strategy research for designing computer-assisted instruction," Journal of Research on Computing in Education, pp. 425-432, 1995.

[11] W. J. M. Levelt, Speaking: From intension to articulation, Cambridge: MIT Press, 1989.

[12] J. C. Richards and W. A. Renandya, Methodology in language teaching, Cambridge University Press, 2002.

[13] H. Riggenbach and A. Lazaraton, promoting oral communication skills, Boston: Heinle \& Heinle, 1991.

[14] A. Cicognani, "Concept Mapping as a Collaborative Tool for Enhanced Online," Educational Technology \& Society, 2000.

[15] W. M. Rivers, Teaching foreign language skills, London: The University Chicago Press, 1981.

[16] K. Shumin, "Factors to Consider: Developing Adult EFL Students' Speaking Abilities," in Methodology in language teaching, Cambridge University Press, 2002, p. Cambridge University Press.

[17] S. D. Ivie, "Ausubel's Learning Theory: An Approach To Teaching Higher Order Thinking," High School Journal, 1998.

[18] R. Oxford, Language learning strategies: What every teacher should know, New York: Newbury House, 1990.

[19] M. Pressly, "Elaboration and memory development," Child Development, pp. 296-309, 1982.

[20] R. L. Oxford, Y. Park-Oh, S. Ito and M. Sumrall, "Effects of motivation, language learning styles and strategies, gender, course level, and previous language learning experiences on Japanese language achievement," Foreign Language Annals, pp. 359-371, 1993.

[21] I. Thompson and J. Rubin, "Can strategy instruction improve listening comprehension?," Foreign Language annals, pp. 331-342, 1996.

[22] B. Zareie, B. Gorjian and A. Pazhakh, "The effect of interactional and transactional speaking strategies on teaching speaking skills to Iranian EFL learners in senior high school level," International Journal of Language Learning and Applied Linguistics World (IJLLALW), pp. 443--459, 2014. 
[23] M. J. Jabbari and R. Sadeghi, "The effect of learning strategies on the speaking ability of Iranian students in the context of language institutes," Asian Journal of Education and eLearning, pp. 82-88, 2014.

[24] S. Hendriani, "Developing amodel oflearning strategy of speaking English at college," International Review of Social Sciences and Humanities, pp. 104-112, 2013.

[25] S. Wahyuni, L2 speaking strategiesemployed by Indonesian EFL tertiary students across profeciency and gender, Canberra: University of Canberra, 2013, p. 300

[26] O. Sabuncuglu, "Effects of learning strategies on students studying language," Fatih Sultan Mehmet Vakif universitesi, 2011.

[27] J. E. Purpura, Learner strategy use and performance on language tests: A structural equation modeling approach, University of Cambridge Local Examination Syndicate: New York, 1999

[28] J. D. Novak, J. J. Mintzes and J. H. Wandersee, "Assessing understanding in biology," Journal of Biological Education, pp. 118-124, 2001.

[29] J. W. Cliburn, "Concept maps to promote meaningful learning," Journal of College Science Teaching, pp. 212-217, 1990.

[30] J. D. Novak, "Concept mapping: A useful tool for science education," Journal of Research in Science Teaching, p. 937949, 1990.

[31] J. D. Novak and J. A. Heinze-Fry, "Concept mapping brings long-term movement toward meaningful learning," Science Education, pp. 461-472, 1990.

[32] I. M. Kuchin, "Effective teacher-student dialogue: a model from biological education," Journal of Biological Education, p. 110-113, 2003.

[33] J. D. Novak, D. B. Gowin and G. T. Johansen, "The use of concept mapping and knowledge vee mapping with junior high school science students," Science Education, p. 625-645, 1983.

[34] P. A. Okebukola and O. J. Jegede, "Cognitive preference and learning mode as determinants of," Science Education, pp. 489-500, 1988.
[35] J. E. Trowbridge and J. H. Wandersee, Theory-driven graphic organizers. In J.Mintzes, J. Wandersee \& J. Novak (Eds.), San Diego: Academic Press, 1996.

[36] J. Palmer, R. T. Boon and V. G. Spencer, "Effects of Concept Mapping Instruction on the Vocabulary Acquisition Skills of Seventh-Graders With Mild Disabilities: A Replication Study," Taylor and Francis Group, pp. 165-182, 2014.

[37] A. B. Cheema and M. S. Mirza, "Effect of Concept Mapping On Students' Academic Achievement," Journal of Research and Reflections in Education, pp. 125-132, 2013.

[38] B. Ghonsooly and A. Hoseinpour, "The effect of concept mapping on EFL speaking fluency," IRANIAN JOURNAL OF APPLIED LINGUISTICS (IJAL), pp. 87-114, 2009.

[39] P. Chularut and T. K. DeBacker, "The influence of concept mapping on achievement, self-regulation, and self-efficacy in students of English as a second language," Contemporary Educational Psychology, p. 248-263, 2003.

[40] K. CHANG, Y. SUNG and I. CHEN, "The Effect of Concept Mapping to Enhance Text Comprehension and Summarization," The Journal of Experimental Education, pp. $5-23,2002$.

[41] T. Nirmala , "CONCEPT MAPPING - AN EFFECTIVE TOOL TO PROMOTE," Nitte University Journal of Health Science, pp. 21-26, 2011.

[42] M. Fahim and M. Mellati, "Concept Mapping: An Influential Factor," Advances in English Linguistics (AEL), pp. 20-24, 2012.

[43] R. Pishghadam and A. Ghanizadeh, "On the impact on concept mapping as a prewriting activity on EFL learners' writing ability," IJAL, pp. 1-26, 2006.

[44] M. Fahim and M. Tabataba'ian, "Concept Maps, Cloze Tests, and Multiple-choice Tests:," Journal of American Science, pp. 131-138, 2012.

[45] E. Shriberg, "Spontaneous Speech: How People Really," INTERSPEECH, pp. 1781-1784, 2005. 